\title{
Comparative Electron-Microscopic Study of Shape Memory Alloys of Systems Cu-Ni-Al and $\mathrm{Ni}-\mathrm{Mn}$-Al
}

\section{Alexey E. Svirid ${ }^{1}$, Elena S. Belosludtseva ${ }^{1}$, Artemy V. Pushin ${ }^{1,2}$, and Vladimir G. Pushin ${ }^{1,2}$}

${ }^{1}$ M.N. Miheev Institute of Metal Physics of Ural Branch of Russian Academy of Sciences (IMP UB RAS), 18 S. Kovalevskaya Street, Ekaterinburg, Russian Federation, 620108;

${ }^{2}$ The First President of Russia B. N. Yeltsin Ural Federal University (UrFU), 19 Mira Street, Ekaterinburg, 620002

\section{Abstract}

The microstructure of $\mathrm{Cu}-\mathrm{Ni}-\mathrm{Al}$ and $\mathrm{Ni}-\mathrm{Mn}-\mathrm{Al}$ alloys in a wide range of chemical compositions has been studied by transmission and scanning electron microscopy methods, diffraction of electrons and X-rays. The phase composition of all the investigated alloys and the mechanism of the fracture under deformation have been

Corresponding Author:

Alexey E. Svirid

svirid2491@rambler.ru

Received: 25 February 2019

Accepted: 9 April 2019

Published: 15 April 2019

Publishing services provided by

Knowledge E

(c) Alexey E. Svirid et al. This

article is distributed under the

terms of the Creative Commons

Attribution License, which

permits unrestricted use and

redistribution provided that the

original author and source are

credited.

Selection and Peer-review under the responsibility of The Ural school-seminar of metal scientists-young researchers Conference Committee.

\section{Introduction}

Thermoelastic martensitic transformations (TMTs) were observed in many binary and multicomponent intermetallic atomic-ordered alloys based on titanium, nickel, and copper: Ti-Ni, Ni-Mn, Ni-Al, Cu-Al, Ti-Ni-Me, Ni-Mn -Me, Ni-Al-Me, Cu-Al-Me and others [1-13]. Doping with third chemical elements allows one to control their critical temperatures $\mathrm{M}_{s}, \mathrm{M}_{f}, \mathrm{~A}_{s}, \mathrm{~A}_{f}$ and to design alloys with specified TMT parameters. At the same time, many aspects of the effect of doping on the features of TMT and the mechanisms of destruction in such alloys remain unexplored.

The most important problem that impedes the practical application of many polycrystalline alloys based on most intermetallic compounds is their relatively low strength, plastic and fatigue characteristics and their tendency to brittle fracture. Thus, polycrystalline $\mathrm{Cu}-\mathrm{Ni}-\mathrm{Al}$ and $\mathrm{Ni}-\mathrm{Mn}-\mathrm{Al}$ alloys experience brittle intercrystalline failure after deformation by $2-3 \%$. The main reasons for this destruction include: a very large elastic anisotropy of their metastable austenite; large grain sizes; the presence of grain-boundary segregations and precipitates of embrittling phases.

Keywords: thermoelastic martensitic transformation, brittleness, fractography, longperiod lattice, electron-microscopic studies. 


\section{Materials and Methods}

In this study we used eleven $\mathrm{Cu}-\mathrm{Al}-3 \mathrm{wt} \% \mathrm{Ni}$ ternary alloys with the content of aluminum varied from 9 to $14 \mathrm{wt} \%$ (with an accuracy of $\pm 0.1 \mathrm{wt} \%$ ), taking into account a triple-point phase-equilibrium diagram of the vertical section of the $\mathrm{Cu}-\mathrm{Al}-\mathrm{Ni}$ three-component system. The alloys were produced by the electric-arc melting from high-purity $\mathrm{Cu}, \mathrm{Al}$ and $\mathrm{Ni}(99.99 \%)$ in a refined helium atmosphere. For the sake of homogenization, the alloys selected by their chemical composition were subjected to long annealing at (1173 $\pm 25) \mathrm{K}$ in an inert argon atmosphere. The alloy ingots were cooled in air. The alloys heated to $1223 \mathrm{~K}$ were forged to form a $12 \times 12 \mathrm{~mm}$ bar, followed by cooling in air. Then they were quenched into water at room temperature after heating of the bars at $1223 \mathrm{~K}$ for $10 \mathrm{~min}$

The alloys based on Ni-Mn-Al system were prepared by induction melting in a purified argon atmosphere. For homogenization, they were remelted (at least three times) and then vacuum annealed at $1173 \mathrm{~K}$ for up to $30 \mathrm{~h}$. High-purity (99.99\% purity) metals served as starting materials for the alloys. Ingots were spark cut into plates, which were then again subjected to homogenizing annealing for $6 \mathrm{~h}$ in the state of $\beta$ (B2) phase followed by water quenching or slow cooling at a rate of $\sim 100 \mathrm{~K} / \mathrm{h}$ from 1073 or $1173 \mathrm{~K}$.

The structure, phase composition, and martensitic transformations were investigated using the methods of X-ray diffraction at $\theta / 2 \theta$ and electron microscopy. The $X$-ray diffraction analysis by the $\theta / 2 \theta$ method was carried out using a DRON-3M diffractometer in the $\mathrm{Cu} K \alpha$ radiation monochromatized by a graphite single crystal. The following facilities of the Ural Branch of RAS, Institute of Metal Physics Collaborative Access Center were used in the investigations: JEM 200 CX (maximum accelerating voltage $200 \mathrm{kV}$ ) and Tecnai G2 30 (maximum accelerating voltage $300 \mathrm{kV}$ ) transmission electron microscopes and a Quanta 200 scanning electron microscope (accelerating voltage $30 \mathrm{kV}$ ) equipped with a Pegasus system. Electron diffraction patterns were taken from a selected area to identify phases.

\section{Results and Discussion}

In the present work, a comparative study of alloys with TMT and the related shape memory effects (SME) of the two doping systems $\mathrm{Cu}-\mathrm{Ni}-\mathrm{Al}$ (9-14 wt.\%) and $\mathrm{Ni}-$ $\mathrm{Mn}-\mathrm{Al}(0-25$ at.\%), created by based on binary alloys Cu-Al and Ni-Mn, is performed. 
By the method of temperature resistometry, it was found that doping with aluminum within the specified limits reduces the critical temperatures of TMT from high to cryogenic. The phase composition of the alloys and the structural types of martensitic phases were determined by X-ray diffraction and the complete phase diagrams of TMT in them were constructed. As aluminum was alloyed, the structural type of martensite also changed: in Ni-Mn-based alloys in the sequence $2 \mathrm{M}\left(\mathrm{L} 1_{0}\right)-14 \mathrm{M}-10 \mathrm{M}$, on the basis of Cu-Al-Ni - from 18R to $4 \mathrm{H}$. The presence of long-period martensitic phases (14M, 10M, $18 \mathrm{R}, 4 \mathrm{H})$ is one of the main differences between these alloys.

According to the TEM data, a common feature of the studied alloys is the multi-packet morphology of pairwise twin martensitic phases (Fig. 1 a, c). The main crystal structure characteristics of the packet morphology of martensite include flat boundaries of primary pairwise twin-oriented crystals and internal nanotwins with crystallographic habits close to $\{110\}$, and special size and orientation relationships. The observed morphology of martensite is, on the whole, typical for martensite in single-crystal alloys of the same compositions. Interpretation of selected area electron diffraction patterns made it possible to determine the structural type of phases. It is shown that the crystal lattices of the both alloys have a complex long-period structure: $\beta_{1}$ - 18R for the $\mathrm{Cu}-14 \% \mathrm{Al}-3 \% \mathrm{Ni}$ alloy and $14 \mathrm{M}$ for the $\mathrm{Ni}_{50} \mathrm{Mn}_{32} \mathrm{Al}_{18}$ alloy. Electron diffraction analysis data are consistent with X-ray studies.

In single crystals of low-modulus non-ferrous alloys with SME, this circumstance is responsible for their high structural-phase and physico-mechanical reversibility in the implementation of TMT under the influence of temperature or external load. However, as a rule, the high brittleness of these alloys in the polycrystalline state prevents the practical application in them of the effects of thermomechanical memory and superelasticity. Therefore, the establishment of the causes of fragility and their elimination is an important scientific and technical task.

A fractographic study of the alloys was performed using SEM in secondary electrons on the samples after testing prior to destruction. In Fig. 2, and the image of the fracture of the samples of the composition $\mathrm{Ni}_{50} \mathrm{Mn}_{50}, \mathrm{Ni}_{50} \mathrm{Mn}_{32} \mathrm{Al}_{18}, \mathrm{Ni}_{50} \mathrm{Mn}_{30} \mathrm{Al}_{20}$, and $\mathrm{Ni}_{50} \mathrm{Mn}_{25} \mathrm{Al}_{25}$ is shown. It can be seen that the destruction occurs in all samples by transcrystalline (mainly along the grain boundaries) and the intercrystalline type (mainly along the joints of packages of martensitic crystals inside the grain). Intercrystalline destruction occurred as brittle as brittle-ductile type. This depends on the arrangement of the packets of martensitic plates relative to the direction of expand of the fracture crack. If the package plane is located along the crack, then brittle fracture occurs (Fig. 2, a - c). This behavior can be explained by the stress concentration in certain areas of the multicrystalline alloy. 

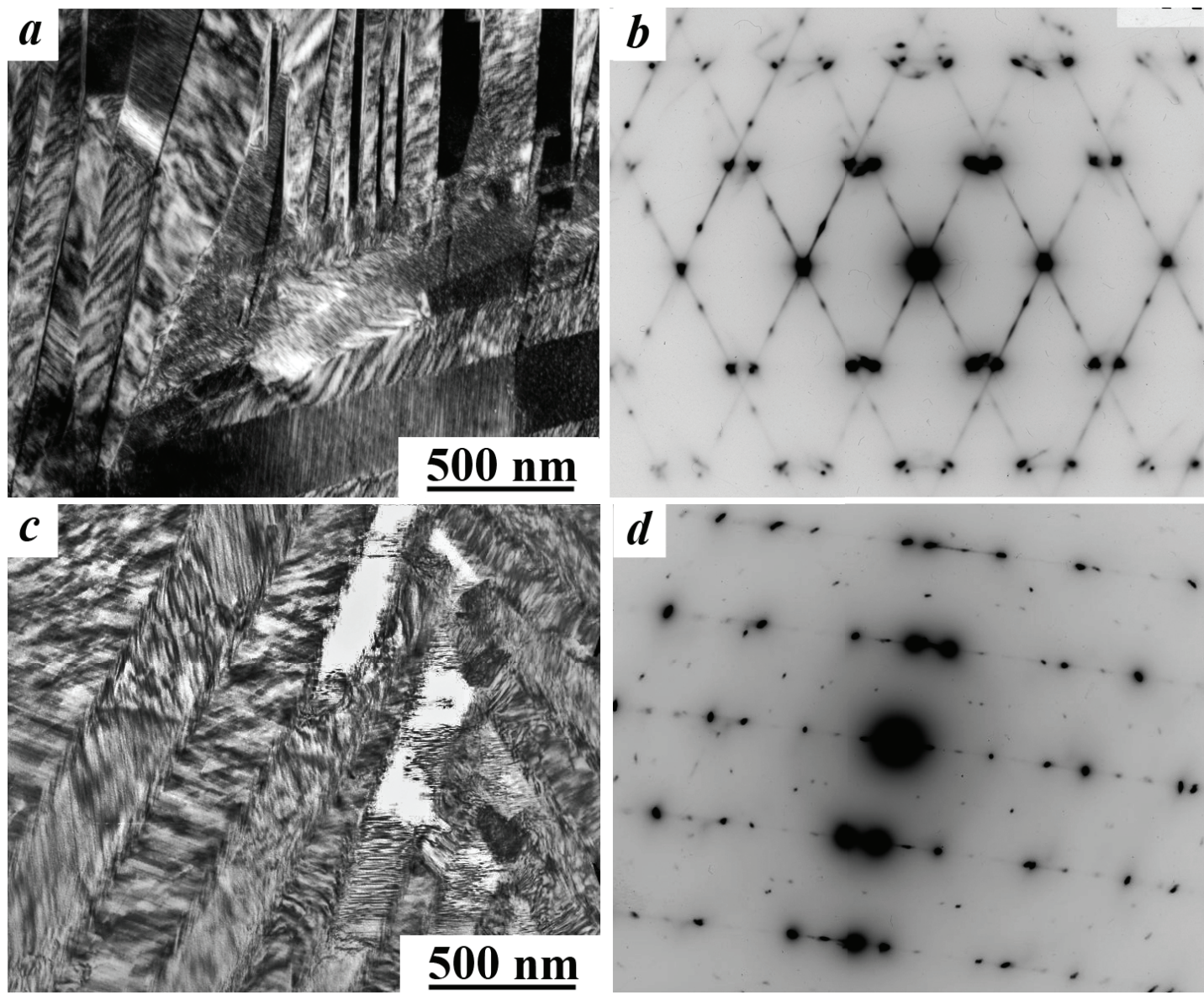

Figure 1: TEM images of the microstructure of the alloys and -Cu-14\% Al-3\% Ni, b- $\mathrm{Ni}_{50} \mathrm{Mn}_{32} \mathrm{Al}_{18}$ and the corresponding selected area electronograms - c, d.

And if a crack develops perpendicularly or at an angle to the habit of the martensitic plates of the package, then a brittle-ductile fracture pattern takes place (Fig. 2, d). With a larger increase on the surface of fracture, one can observe a number of areas characterized by lamellar relief.

The nature of fracture under tension of samples of coarse-grained Cu-Ni-Al alloys, as a rule, was intergranular brittle, and in more fine-grained alloys it became ductile (cf. Fig. 3 a, b) or mixed ductile-brittle (Fig. 3 c, d).

At the same time, according to mechanical test data, the ultimate strength $\sigma_{u}$, the yield strength $\sigma_{y}$, and the relative elongation $\delta$ changed at room temperature. The increase in the mechanical properties of the alloys was due to the refinement of the grain structure of the $\beta$-austenite and the packet substructure. So, for fine-grained alloys with 9.2 and $9.5 \mathrm{wt}$ \% Al, the value of relative elongation is maintained at a good level (>10\%), and for other alloys with an aluminum content of 10-14 wt. \%, It does not exceed $5 \%$. With a change in the aluminum content in these alloys, the nature of the destruction of the samples under uniaxial tension also changes. 

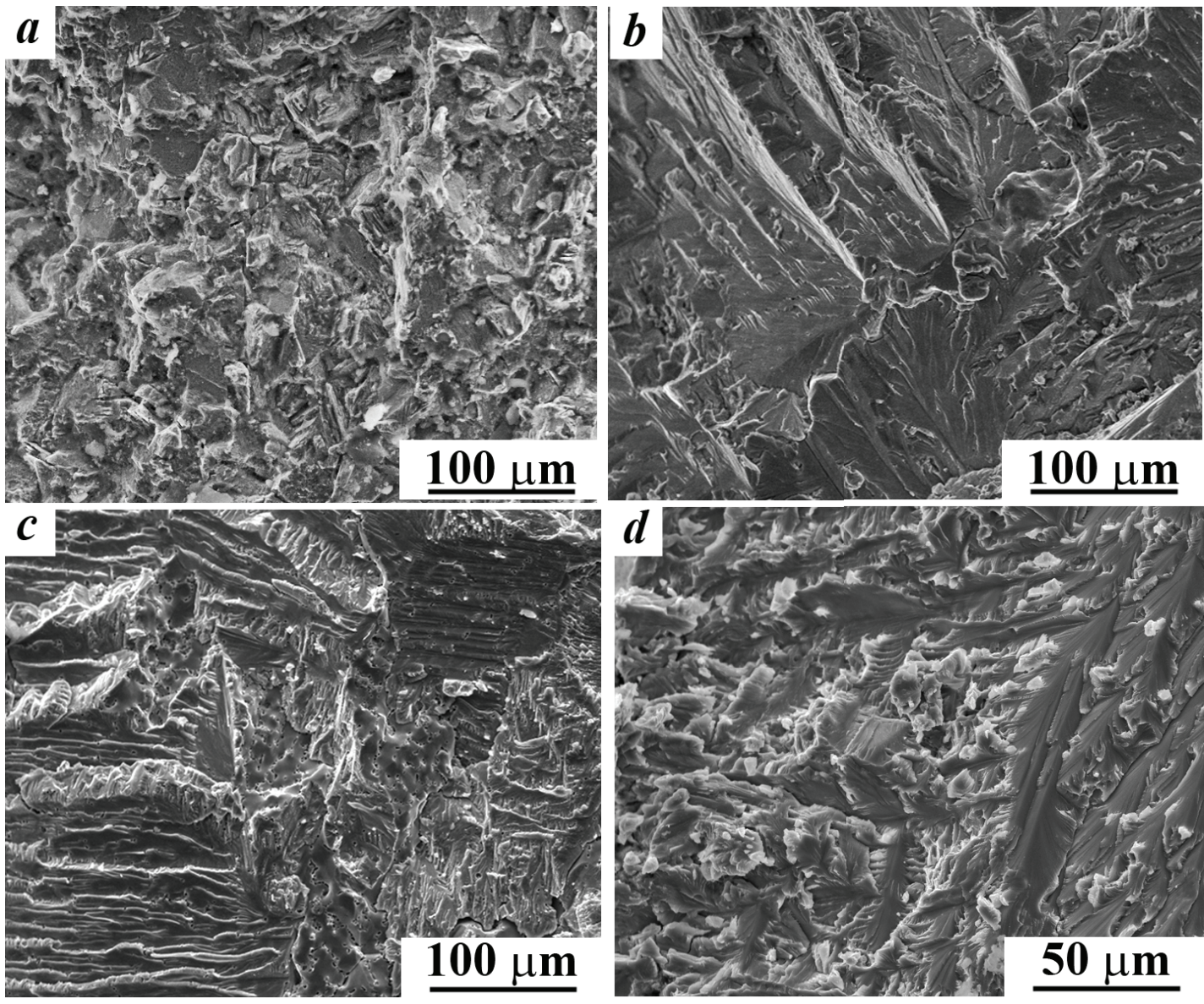

Figure 2: Fractography of alloys a - $\mathrm{Ni}_{50} \mathrm{Mn}_{50}$, b - Ni $\mathrm{Ni}_{50} \mathrm{Mn}_{32} \mathrm{Al}_{18}, \mathrm{c}-\mathrm{Ni}_{50} \mathrm{Mn}_{30} \mathrm{Al}_{20}, \mathrm{~d}-\mathrm{Ni}_{50} \mathrm{Mn}_{25} \mathrm{Al}_{25}$.

\section{Summary}

The following main patterns of structural and phase changes occurring in the Cu-Al-Ni and $\mathrm{Ni}-\mathrm{Mn}$-Al alloys during various deformation-thermal treatments were established:

1. The factors determining the embrittlement of polycrystalline alloys in the martensitic state are the magnitude and anisotropy of the elastic moduli, the difference in the lattice parameters of martensitic phases from the corresponding parameters of the initial phase, grain sizes and the presence of excess phases, especially at the boundaries of the original grains.

2. The alloying of these alloys with aluminum makes it possible to control their critical temperatures $\mathrm{M}_{s}, \mathrm{M}_{f}, \mathrm{~A}_{s}, \mathrm{~A}_{f}$ from high to cryogenic and to design alloys with given TMT parameters.

3. As the aluminum was doped, the structural type of martensite changed: in Ni-Mnbased alloys in the sequence $2 \mathrm{M}\left(\mathrm{L1}_{0}\right)$ - 14M - 10M, on the basis of Cu-Al-Ni - from 

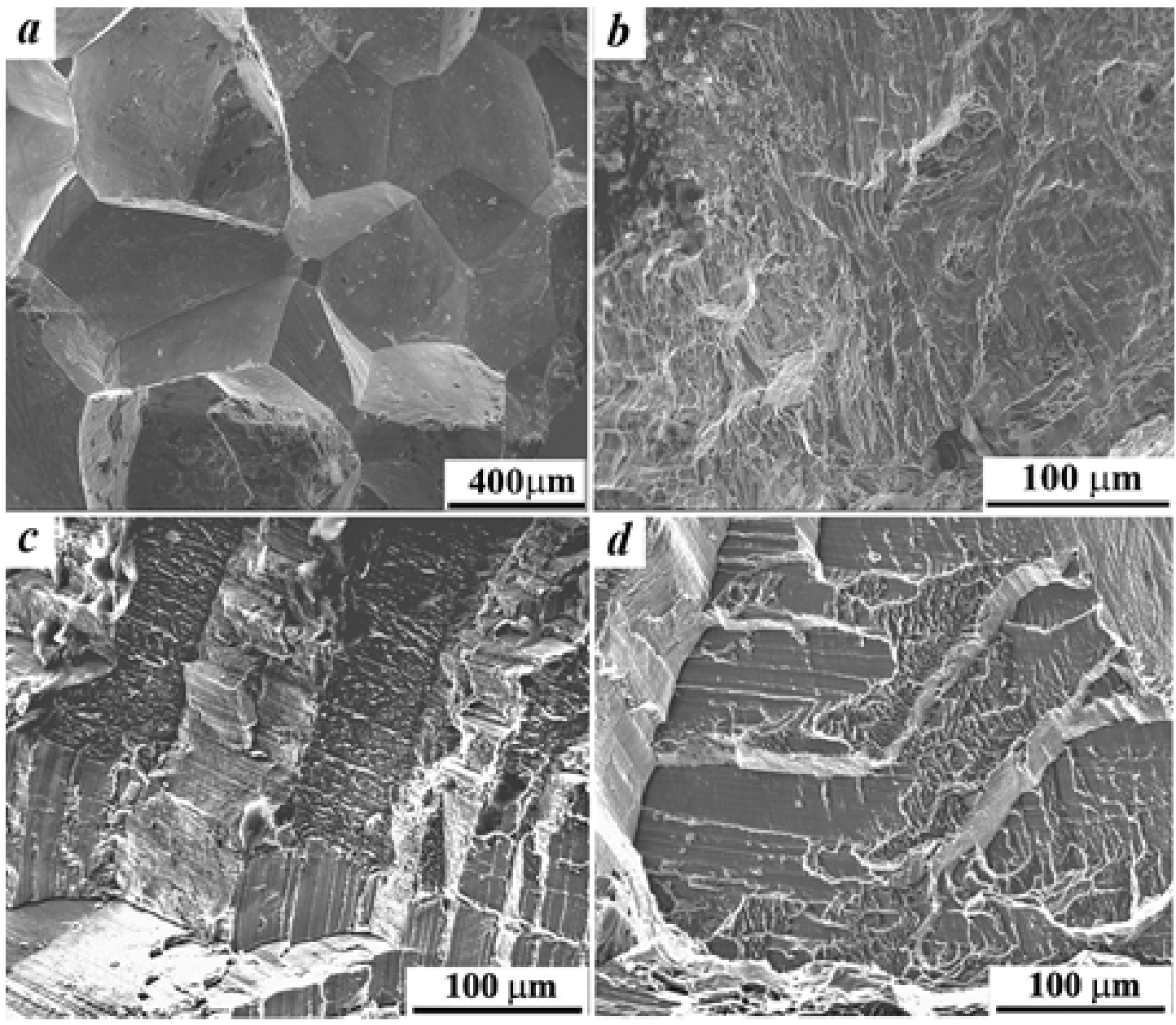

Figure 3: Fractography of alloys a - Cu-14\% Al-3\% Ni, b - Cu-9.2\% Al-3\% Ni, c - Cu-10\% Al-3\% Ni, d - Cu-12\% Al $-3 \% \mathrm{Ni}$.

$18 \mathrm{R}$ to $4 \mathrm{H}$. The presence of long-period martensitic phases is one of the main differences between these alloys.

4. It was established that a common feature of the studied alloys is the multi-packet morphology of pairwise twin martensitic phases, which are characterized by flat boundaries of primary pairwise twin-oriented crystals and internal nanotwins with crystallographic habits close to $\{110\}$ and Bain type OR.

5. Different, depending on the aluminum content, refinement of the grain structure influences the deformation behavior of the alloys, leading to an increase in their strength and plastic properties. In this case, the mechanism of their destruction changes from brittle (along the boundaries of the former austenitic grains and / or the boundaries of martensite packets in a hot-rolled and hardened state) to a predominantly brittle-ductile fracture (with the development of significant preliminary plastic deformation). 


\section{Acknowledgment}

The work was carried out within the framework of the state task of Russian Ministry of Education and Science (cipher "Structure", No. AAAA-A18-118020190116-6) and with partial support of the RFBR (project No. 18-32-00529 mol_a).

\section{References}

[1] Pre-transition phenomena and martensitic transformations, V.G. Pushin, V.V. Kondrat'ev, Physics of Metals and Metallography. 78(5) (1994) 40-61.

[2] V.G. Pushin, S.D. Prokoshkin, R.Z. Valiev et all, Alloys of nickel titanium with shape memory. Part 1 Structure, phase transformations and properties, ed. by V.G. Pushin, UB of RAS, Ekaterinburg, 2006

[3] Effect of Aluminum Alloying on the Structure, the Phase Composition, and the Thermoelastic Martensitic Transformations in Ternary Ni-Mn-Al Alloys,E. S. Belosludtseva, N. N. Kuranova, N. I. Kourov, V. G. Pushin, V. Yu. Stukalov, A. N. Uksusnikov, Technical Physics. 60 (2015) 1000-1004.

[4] Effect of the Thermomechanical Treatment on Structural and Phase Transformations in $\mathrm{Cu}-14 \mathrm{Al}-3 \mathrm{Ni}$ Shape Memory Alloy Subjected to High-Pressure Torsion, A. V. Lukyanov, V. G. Pushin, N. N. Kuranova, A. E. Svirid, A. N. Uksusnikov, Yu. M. Ustyugov, D. V. Gunderov, Physics of Metals and Metallography. 119 (2018) 374-383.

[5] V.G. Pushin, N.N. Kuranova, E.B. Marchenkova, E.S. Belosludtseva et. all, Thermoelastic Martensitic Transitions and Shape Memory Effects: Classification, Crystal and Structural Mechanisms of Transformations, Properties, Production and Application of Promising Alloys, in: V.V. Rubanik, N.N. Resnina (Eds.), Shape memory alloys: properties, technologies, opportunities, Trans. Tech. Publication, Switzeland, 2015.33 pp. 978-3-03835-357-7

[6] E.S. Belosludtseva, N.N. Kuranova, N.I. Kourov, V.G. Pushin, V.Yu. Stukalov, A.N. Uksusnikov, Effect of aluminum alloying on the structure, the phase composition, and the thermoelastic martensitic transformations in ternary $\mathrm{Ni}-\mathrm{Mn}-\mathrm{Al}$ alloys, Technical Physics. 60 (2015) 1000-1004.

[7] E.S. Belosludtseva, N.N. Kuranova, E.B. Marchenkova, V.G. Pushin, Features of thermoelastic martensitic, structure and properties in ternary B2-alloys based on $\mathrm{NiMn}$ - NiTi, NiMn - NiAl, NiMn - NiGa, $\mathrm{N}_{i 2} \mathrm{MnGa}-\mathrm{Ni}_{3}$ Ga quasi-binary systems, Materials Today: Proceedings. 4 (2017) 4717-4721 
[8] E.S. Belosludtseva, V.G. Pushin, E.B. Marchenkova, A.E. Svirid, A.V. Pushin, Investigation of Intermetallic Alloys Based on Ni-Mn with Controlled Shape Memory Effect Materials, Research Proceedings 9 (2018) 14-18.

[9] V.G. Pushin, E.S. Belosludtseva, E.B. Marchenkova, Multicomponent Metallic NiMn-Based Alloys with Thermally, Mechanically and Magnetically Controlled Shape Memory Effects, Physics of Metals and Metallography. 119 No. 12 (2018) 1191-1195.

[10] A.E. Svirid, V.G. Pushin, N.N. Kuranova, A.V. Luk'yanov, A.V. Pushin, A.N. Uksusnikov, Y.M. Ustyugov, The structure-phase transformations and mechanical properties of the shape memory effect alloys based on the system $\mathrm{Cu}-\mathrm{Al}-\mathrm{Ni}$, Materials Today: Proceedings 4 (2017) $4758-4762$.

[11] A. V. Lukyanov, V. G. Pushin, N. N. Kuranova, A. E. Svirid, A. N. Uksusnikov, Yu. M. Ustyugov, D. V. Gunderov, Effect of the thermomechanical treatment on structural and phase transformations in Cu-14Al-3Ni shape memory alloy subjected to high pressure torsion, Physics of Metals and Metallography. 119 (2018) 374-383.

[12] A.V. Lukyanov, A.E. Svirid, A N. Uksusnikov, The effect of high-temperature thermomechanical processing and severe plastic torsional deformation on the structuralphase transformations and properties of Cu-Al-Ni alloys with shape memory effect, in V.V. Klubovich (Eds) Monograph, Belarus, Vitebsk "VSTU", 2017 - 467 p.

[13] A.E. Svirid, N.N. Kuranova, A.V. Lukyanov, V.V. Makarov, N.V. Nikolayeva, V.G. Pushin, A.N. Uksusnikov, The influence of thermomechanical processing on the structurephase transformations and mechanical properties of Cu-Al-Ni alloys with shape memory, Russian Physics Journal. in the press. 